\title{
The UV-A and visible solar irradiance spectrum: inter-comparison of absolutely calibrated, spectrally medium resolution solar irradiance spectra from balloon- and satellite-borne measurements
}

\author{
W. Gurlit ${ }^{1}$, H. Bösch ${ }^{2, *}$, H. Bovensmann ${ }^{1}$, J. P. Burrows ${ }^{1}$, A. Butz ${ }^{2}$, C. Camy-Peyret ${ }^{3}$, M. Dorf ${ }^{2}$, K. Gerilowski ${ }^{1}$, \\ A. Lindner ${ }^{2}$, S. Noël ${ }^{1}$, U. Platt ${ }^{2}$, F. Weidner ${ }^{2}$, and K. Pfeilsticker ${ }^{2}$ \\ ${ }^{1}$ Institut für Umweltphysik und Fernerkundung, University of Bremen, Bremen, Germany \\ ${ }^{2}$ Institut für Umweltphysik, University of Heidelberg, Heidelberg, Germany \\ ${ }^{3}$ Laboratoire de Physique Moléculaire et Applications (LPMA), Université Pierre et Marie Curie, Paris, France \\ * now at: Jet Propulsion Laboratory (JPL), California Institute of Technology, Pasadena, USA
}

Received: 9 August 2004 - Published in Atmos. Chem. Phys. Discuss.: 20 December 2004

Revised: 20 June 2005 - Accepted: 27 June 2005 - Published: 26 July 2005

\begin{abstract}
Within the framework of the ENVISAT/SCIAMACHY satellite validation, solar irradiance spectra are absolutely measured at moderate resolution in the UV/visible spectral range (in the UV from $316.7-418 \mathrm{~nm}$ and the visible from $400-652 \mathrm{~nm}$ at a full width half maximum resolution of $0.55 \mathrm{~nm}$ and $1.48 \mathrm{~nm}$, respectively) from aboard the azimuth-controlled LPMA/DOAS balloon gondola at around $32 \mathrm{~km}$ balloon float altitude. After accounting for the atmospheric extinction due to Rayleigh scattering and gaseous absorption $\left(\mathrm{O}_{3}\right.$ and $\left.\mathrm{NO}_{2}\right)$, the measured solar spectra are compared with previous observations. Our solar irradiance spectrum perfectly agrees within $+0.03 \%$ with the re-calibrated Kurucz et al. (1984) solar spectrum (Fontenla et al., 1999, called MODTRAN 3.7) in the visible spectral range $(415-650 \mathrm{~nm})$, but it is $+2.1 \%$ larger in the (370$415 \mathrm{~nm}$ ) wavelength interval, and $-4 \%$ smaller in the UV-A spectral range $(316.7-370 \mathrm{~nm})$, when the Kurucz spectrum is convolved to the spectral resolution of our instrument. Similar comparisons of the SOLSPEC (Thuillier et al., 1997, 1998a, b) and SORCE/SIM (Harder et al., 2000) solar spectra with MODTRAN 3.7 confirms our findings with the values being $-0.5 \%,+2 \%$, and $-1.4 \%$ for SOLSPEC $-0.33 \%$, $-0.47 \%$, and $-6.2 \%$ for SORCE/SIM, respectively. Comparison of the SCIAMACHY solar spectrum from channels 1 to 4 (- re-calibrated by the University of Bremen -) with MODTRAN 3.7 indicates an agreement within $-0.4 \%$ in the visible spectral range $(415-585 \mathrm{~nm}),-1.6 \%$ within the 370 $415 \mathrm{~nm}$, and $-5.7 \%$ within $325-370 \mathrm{~nm}$ wavelength interval, in agreement with the results of the other sensors. In agreement with findings of Skupin et al. (2002) our study emphasizes that the present ESA SCIAMACHY level 1 calibration
\end{abstract}

Correspondence to: K. Pfeilsticker

(klaus.pfeilsticker@iup.uni-heidelberg.de) is systematically $+15 \%$ larger in the considered wavelength intervals when compared to all available other solar irradiance measurements.

\section{Introduction}

Solar radiation is the driving force for climate, and thus for life on Earth. It has long been speculated that changes in the total solar irradiance either due to temporal variations in solar physics related processes or due to changes in the orbital parameters of the Earth may affect the climate on time scales ranging from geological times $\left(\sim 10^{9} \mathrm{yrs}\right)$ down to several years, e.g., due to the strength of the 11 year solar cycle (IPCC, 2001). For example, the total solar irradiance $\left(\mathrm{S}_{o}\right)$ is known to change by $\pm 1.3 \mathrm{~W} / \mathrm{m}^{2} \pm 0.1 \%$ within the 28 days solar rotation cycle and 11 year semi-cycle in the Sun's magnetic polarity. For both cycles, the largest relative changes (up to a factor of 2) occur for wavelengths $<300 \mathrm{~nm}$ (e.g., Willson, 1997; IPCC, 2001). Fortunately for life on Earth, smaller relative changes in the spectral irradiance occur in both cycles (on the order of $10^{-3}$ relative change) for wavelengths $>300 \mathrm{~nm}$. Annual variations of $\mathrm{S}_{o}( \pm 3.5 \%)$ due to the Earth eccentricity are important as well, but in measurements these variations are usually removed by relating the individual measurements to the average Earth/Sun distance. Evidently, the extraterrestrial solar irradiance spectrum (further on called $\mathrm{E}_{o}(\lambda)$ ) and its temporal variation is quite of some interest for atmospheric spectroscopy, photochemistry, climate and the solar cell industry as well. For spectroscopists (and solar physicists), potential changes of the Sun-disk average in the optical thickness of the solar Fraunhofer lines (cf., Bösch et al., 2003) are most important,

(C) 2005 Author(s). This work is licensed under a Creative Commons License. 
since sensitive UV/visible spectroscopy in planetary atmospheres largely relies on removing the Fraunhofer lines in ratioed spectra. To date little is known about the Sun disk average spectroscopic parameters and in particular about the temporal and spatial variability of individual Fraunhofer lines.

In the past two decades, information on the solar constant and $\mathrm{E}_{o}(\lambda)$ were collected by a large number of space-borne, air-borne and ground-based instruments (e.g., Neckel and Labs, 1984; Kurucz et al., 1984, 1992; Wehrli, 1985; Brault and Neckel, 1987; Thuillier et al., 1997, 1998a, b; Harrison et al., 2003). To date, a consensus on $\mathrm{E}_{o}(\lambda)$ could only be achieved within few percents in the UV-A and visible spectral range, primarily due to given problems with the absolute calibration of radiation measurements, long term drifts of the various employed sensors, and resulting inter-calibration errors.

For the present study most important are the high resolution spectrum measured by Kurucz et al. (1984) calibrated with Neckel and Labs (1984) solar line data which forms the basis for the WMO consensus (Wehrli, 1985), and the recent spectro-radiometrically re-calibrated Kurucz et al. solar spectrum (Fontenla et al., 1999, in the manuscript briefly called MODTRAN 3.7) using spectro-radiometric data from the space-borne SOLSPEC instrument, (Thuillier et al., 1997, 1998a, b). These spectra are compared with our balloon-borne $\mathrm{E}_{o}(\lambda)$-measurements conducted at $32 \mathrm{~km}$ altitude. Unfortunately, our $\mathrm{E}_{o}(\lambda)$ spectrum can not be compared with $\mathrm{E}_{o}(\lambda)$ recently inferred by Harrison et al. (2003), since the authors did not make their solar spectrum available to the public.

Here direct Sun observations of the LPMA/DOAS payload (Limb Profile Monitor of the Atmosphere and Differential Optical Absorption Spectroscopy) are used to absolutely infer $\mathrm{E}_{o}(\lambda)$ in 2 wavelength intervals in the UV/visible spectral range (316.7-418 nm, 400-652 nm). During past balloon flights the primary scientific objective of the LPMA/DOAS payload was the simultaneous measurement of profiles of atmospheric trace gases which are of interest for the ozone chemistry, such as $\mathrm{O}_{3}, \mathrm{O}_{4}, \mathrm{NO}, \mathrm{NO}_{2}, \mathrm{HNO}_{3}, \mathrm{BrO}, \mathrm{OClO}$, $\mathrm{HCl}, \mathrm{ClONO}_{2}, \mathrm{IO}, \mathrm{OIO}, \mathrm{CO}, \mathrm{CO}_{2}, \ldots$ (for details of the instruments and the measurements see Camy-Peyret et al., 1993; Payan et al., 1998; Harder et al., 1998, 2000; Ferlemann et al., 1998, 2000; Bösch et al., 2001, 2003; Pfeilsticker et al., 2000, 2001). The used instrumentation and observation geometry provided by the balloon gondola are also ideally suited to support precise $\mathrm{E}_{o}(\lambda)$-measurements. Our in-flight measured $\mathrm{E}_{o}(\lambda)$ is corroborated by a spectroradiometric calibration of the deployed spectrometers using on-site calibration instruments prior to the balloon flights. The $\mathrm{E}_{o}(\lambda)$-measurement includes suitable corrections to the atmospheric extinction, which is based on Langley's method in order to account for the residual atmospheric extinctions due to Rayleigh- and Mie-scattering, and trace gas absorptions of $\mathrm{O}_{3}, \mathrm{NO}_{2}, \mathrm{BrO}, \ldots$
In the past 2.5 years SCIAMACHY (Scanning Imaging Absorption Spectrometer for Atmospheric CHartographY) has been monitoring daily $E_{o}(\lambda)$ within the 220 $2380 \mathrm{~nm}$ wavelength range. These observations form a unique, and unprecedented set of $\mathrm{E}_{o}(\lambda)$-measurements when carefully validated. Intentionally, our balloon-borne $\mathrm{E}_{o}(\lambda)$ measurements are primarily motivated to validate those of the SCIAMACHY instrument (e.g., Burrows et al., 1995; Frerick et al., 1997; Bovensmann et al., 1999), but due to their high quality they are evidently suitable to test previous $\mathrm{E}_{o}(\lambda)$-measurements and their derivates (e.g., Kurucz et al., 1984; Neckel and Labs, 1984; Wehrli, 1985; Fontenla et al., 1999; Thuillier et al., 1997 1998a, b; Harrison et al., 2003).

Here we report on UV/visible $\mathrm{E}_{o}(\lambda)$-measurements from SCIAMACHY and the LPMA/DOAS balloon instruments. Results of the near-IR $\mathrm{E}_{o}(\lambda)$-measurements will be reported elsewhere.

The present study is organized as follows: In Sect. 2, we describe and discuss the employed methods. Section 3 is devoted to the description of the absolute calibrations of the balloon-borne and the SCIAMACHY instrument. Section 4 reports on the field observations, and Sect. 5 discusses the results. Finally, Sect. 6 closes the study with concluding remarks.

\section{Methods}

\subsection{The LPMA/DOAS payload}

The azimuth-controlled French/German LPMA/DOAS gondola carries 3 optical spectrometers (two grating DOAS spectrometers from the Institut für Umweltphysik, University Heidelberg, Germany and a Bomen FT-IR from the Laboratoire de Physique Moléculaire et Applications (LPMA) at the Université Pierre et Marie Curie, Paris, France). The set of spectrometers covers the wavelength range from $316.7 \mathrm{~nm}$ to $2400 \mathrm{~nm}$, being more or less the same wavelength range as the SCIAMACHY instrument encompasses (for the balloon payload and deployed instruments see Camy-Peyret et al., 1993 and Ferlemann et al., 2000, and for SCIAMACHY Bovensmann et al., 1999). The balloon payload's azimuth control is based on technologies developed by the Observatoire de Genève in the past 20 years (Huguenin, 1994). The scanning of the solar disk during the flight is performed by an automated telescope, in detail described by Hawat et al. (1998). The telescope is equipped with two coated plane aluminium ( $\mathrm{Al}$ ) mirrors that allow a pointing to the center of the solar disk within $1^{\prime}$. It provides a parallel beam of about $10 \mathrm{~cm}$ in diameter to the three spectrometers. Furthermore, all angles relevant for the gondola and Sun-tracker orientation relative to the Sun are recorded, an information which is necessary for the attitude control of the measurements. 


\subsection{The DOAS instrument}

Since the details of the DOAS spectrometer have already been described elsewhere (Ferlemann et al., 2000), here only a short description of its key features is given. Two small (light intake) telescopes are mounted at the outer edge of the parallel solar beam provided by the Sun-tracker. They are equipped with appropriate filters, lenses, diffusers and skimmer plates which provide a field of view, $\mathrm{FOV}=10^{\circ}$ and $16^{\circ}$, f/5.7 and $\mathrm{f} / 3.5$ for the UV and visible instruments, respectively. This optical arrangement of the telescopes allows observation of the full solar disk $\left(0.55^{\circ}, \mathrm{f} / 55\right)$, which is necessary for reliable atmospheric trace gas measurements and radiometric calibrated $\mathrm{E}_{o}(\lambda)$-measurements (Bösch et al., 2003). From the telescope exits, two quartz fibre bundles conduct the collected light into two grating spectrometers. Both spectrometers are mounted into an evacuated, and thermostated spectrometer housing $\left(0.0 \pm 0.3^{\circ} \mathrm{C}\right)$, a feature which keeps the optical imaging reasonably constant during the balloon flights. The exits of the quartz fibre bundles form rectangular slits $(125 \mu \mathrm{m}$ in width and $2.5 \mathrm{~mm}$ in height). Holographic gratings disperse the solar light onto photodiode detector arrays in the respective wavelength intervals (UV: $316.7-418 \mathrm{~nm}$ and visible: $400-652 \mathrm{~nm}$ ). The width of the slits $(125 \mu \mathrm{m}$ corresponding to the width of 5 photodiode pixels) are chosen to provide full width half maximum (FWHM) resolutions of $0.45 \mathrm{~nm}$ (or $\sim 0.112 \mathrm{~nm} /$ diode), and $1.48 \mathrm{~nm}$ (or $\sim 0.257 \mathrm{~nm} /$ diode) for the UV and visible instrument, respectively. The light is detected by two state of the art 1024 element photodiode array detectors cooled to $-10^{\circ} \mathrm{C}$ with on-chip integrated Peltier elements (Hamamatsu S5931-1024N). The frequently used sapphire window - usually used to protect the photodiode array surface - is removed to avoid disturbing reflections of the incoming light, a measure decreasing the unwanted spectrometer stray light. The photodiode outputs are pre-amplified and fed into two 16 bit A/D converters and read-out by two 68332-CPU driven controller devices. The total read-out time of the electronics is about $60 \mathrm{~ms}$ for 1024 diodes allowing us to record individual spectra within $\sim 100 \mathrm{~ms}$. Both 68332 -CPU controllers are supervised by a 486-PC single board which also controls the onboard data storage as well as the communication to the ground station via telemetry/telecommand.

\subsection{The ENVISAT/SCIAMACHY instrument}

SCIAMACHY deployed onboard the ESA ENVISAT satellite is an optical spectrometer designed to measure sunlight, transmitted, reflected and scattered by the Earth atmosphere or surface in the ultraviolet, visible and near infrared wavelength region $(240 \mathrm{~nm}-2380 \mathrm{~nm})$ at moderate spectral resolution $(0.2-1.5 \mathrm{~nm})$. ENVISAT was launched into orbit from Kourou on 28 February 2002 on a Sun synchronous orbit with an equator crossing time at roughly 10:00 LT. SCIAMACHY measures the absorption, reflection and scattering characteristics of the atmosphere by monitoring the extraterrestrial solar irradiance and the upwelling radiance observed in different viewing geometries. The ratio of measured $\mathrm{E}_{o}(\lambda)$ and the upwelling radiance is inverted to provide information about the amounts and distribution of important atmospheric constituents, which absorb or scatter light, and the spectral reflectance (or albedo) of the Earth's surface (for details on the instrument see Burrows et al., 1995, Frerick et al., 1997 and Bovensmann et al., 1999, and for first measurements see Von Savigny et al., 2004a, b).

Several types of $\mathrm{E}_{o}(\lambda)$-measurements are regularly performed by SCIAMACHY as part of the in-flight calibration and monitoring concept (e.g., Noël et al., 2003).

\subsection{The calibration sources}

For the absolute radiometric calibration, the following radiation sources and standards are used:

Calibrated NIST lamps: For the absolute calibration, a National Institute of Standards and Technology (NIST) FEL 1000 W irradiance standard Quartz Tungsten Halogen (QTH) lamp (serial number F-455) from OSRAM Sylvania is used as radiation standard (see below) (Walker et al., 1987). The lamp emits sufficient light in the $250-2400 \mathrm{~nm}$ wavelength range, with a maximum output at $900 \mathrm{~nm}$, from a $\sim 35 \mathrm{~mm}$ large spiral-wound filament. In the UV/visible spectral range (350-652 nm), the wavelength dependent radiometric accuracies range between $0.91 \%-1.09 \%$, and the long term reproducibility is $0.87 \%-0.96 \%$ depending on the wavelength (for details see NIST report of calibration, 844/25 70 96-961, 1997).

Sun simulator: Since the balloon-borne LPMA/DOAS spectrometers analyze the solar light from a parallel beam of $10 \mathrm{~cm}$ diameter, a Sun simulator for laboratory test measurements has been built. The Sun simulator consists of a small passively cooled reflective diffuser plate of $9.2 \mathrm{~mm}$ diameter which is uniformly illuminated by 4 stabilized $250 \mathrm{~W}$ reflector QTH lamps. The small diffuser plate is imaged into infinity through a $200 \mathrm{~mm}$ diameter, $\mathrm{f}=1000 \mathrm{~mm}$, offaxis parabolic mirror. It produces a collimated beam with a divergence of about $0.52^{\circ}$. The diffuser plate is mounted into the focus of the collimating mirror for the emission of a nearly homogeneous beam across its principal axis. In longitudinal direction, the beam homogeneity is given by the diameter of the reflective diffuser, the focal length of the parabolic mirror and the diameter of the parabolic mirror. In this region, the irradiance across the beam (diameter $12 \mathrm{~cm}$ ) remains constant to within $\pm 2 \%$ and along the major beam axis it changes by less than $1 \% / \mathrm{m}$.

The long term stability of the Sun simulator $(1 \% / 24 \mathrm{~h})$ is tested by regularly monitoring its output with a stabilized photometer, equipped with a bandpass filter centered at $400 \mathrm{~nm}$ and of $30 \mathrm{~nm}$ band width. For intermediate radiometric standard, a small and thermostated Ocean Optics USB2000 spectrometer, equipped with a PTFE diffuser plate light 
intake telescope is used in cross calibration exercises (see below).

Prior to the absolute calibration of the in-flight spectrometers, the NIST lamp is used to calibrate the output of the Sun simulator using the Ocean Optics USB-2000 spectrometer. The cross calibration involves two steps. First, the Ocean Optics USB-2000 spectrometer is calibrated with radiation measurements taken from the absolutely calibrated NIST lamp. For this purpose, the NIST lamp, the USB-2000 spectrometer entrance optics, and the Sun simulator beam center are properly aligned on an optical bench. Later a light trap is installed in between the turned-off Sun simulator and the NIST lamp. Calibration of the USB-2000 spectrometer is performed by directing its light intake optics into the center of the NIST lamp. Then the light trap and the NIST lamp are dismounted. Using the calibrated USB-2000 spectrometer, the beam irradiance of the Sun simulator is measured as a function of distance by moving the entrance optics of the USB-2000 spectrometer along the Sun simulator beam. The measurements provide information on the Sun simulator beam homogeneity, and on its absolute irradiance as function of beam position. The whole set of inter-calibrated instruments (NIST lamp, Sun simulator and the USB-2000 spectrometer) is further used to calibrate both DOAS spectrometers. Evidently, the set of instruments allows a closed loop calibration using either the NIST lamp or the calibrated Sun simulator as standard (see Sect. 3).

\section{Absolute radiometric calibration of the field instru- ments}

\subsection{Calibration of the DOAS spectrometers}

The LPMA/DOAS payload represents an optical system with 4 subsystems: (1) the Sun-tracker, (2) the LPMA Fourier Transform instrument, (3) the DOAS UV and (4) visible telescope. Ideally, all these optical devices should exactly point into the same direction, but in reality they are only more or less well aligned.

The pre-flight absolute calibration of the LPMA/DOAS spectrometers involves the following 5 steps:

1. The optical alignment of all 3 spectrometers is individually optimized by maximizing the received solar light when the Sun-tracker points to the solar disk's center. This "best" position of the Sun-tracker is documented by imaging the solar disk with a CCD camera, which is mounted into the viewing direction of the Sun-tracker. The Sun-tracker's maximum signal position is referred to as the Sun-tracker "zero position". After this procedure is performed, small misalignments (pointing errors) of each of the 3 spectrometers with respect to the Sun-tracker zero position may however, remain.
2. In the second step, the relative alignment of the optical axis of each spectrometer and the Sun-tracker are tested using the Sun simulator. For this purpose, the beam of the Sun simulator is directed towards the Sun-tracker which is kept in its "zero" position. Information on remaining misalignments of the spectrometer's optical axis with respect to the Sun-tracker "zero position" is further gained by varying the azimuth and elevation angles of the Sun-tracker (within the possible limits given by the set-up, see point 5 below) and by monitoring the spectra of the Sun simulator. Then the received maximum signal defines the misalignment of each spectrometer and the necessary pointing corrections.

3. After quantification of the pointing errors for the different spectrometers (using the Sun simulator as a small light source positioned at infinity), both DOAS spectrometers can be absolutely calibrated with a point source (the NIST lamp) aligned at finite (known) distance. For this purpose an alignment diode laser and the NIST lamp are mounted on an optical bench $(4 \mathrm{~m}$ long) which is installed roughly $3 \mathrm{~m}$ in front of the Suntracker. The relative alignment of each spectrometer light intake is measured by directing the laser beam first through the center of a moveable graticule (the socalled alignment-"jig" recommended by NIST; Walker et al., 1987), and the centers of the DOAS telescopes. For this purpose the alignment-"jig" is mounted into the NIST lamp holder on the optical bench. Further, the alignment-"jig" is replaced by the NIST lamp and the irradiance received by each spectrometer is maximized by turning the Sun-tracker into the maximum signal position of each spectrometer. In a next step, the NIST lamp is again replaced by the alignment-"jig". The optical axis defined by the alignment-"jig" and the DOAS telescope's centers is further geometrically measured by pointing with a theodolite through the graticule and each telescope center. The optical bench is fine adjusted by moving the graticule to different bench positions, while pointing with the theodolite through the graticule's center. After this procedure, the optical axis of each DOAS telescope is reproducibly defined relative to the optical bench. Further, using the theodolite and small retroreflectors positioned in front of the graticule and the telescopes, electro optical distance measurements are performed to within $0.1 \%$ precision. The knowledge of the distance between the calibration source and the telescopes is necessary for the calculation of the lamps irradiance at that distance (see point 4).

4. Before the final radiometric calibration can be made, the emission of the NIST-lamp is monitored using the flight spectrometers while moving the NIST lamp along the optical bench. This test provides information on the square distance behaviour of the measured irradiance $\mathrm{E}$ 
Table 1. Error budget of the absolute $\mathrm{E}_{o}(\lambda)$-measurements in the UV and visible channels of DOAS on the LPMA/DOAS payload.

\begin{tabular}{|c|c|c|c|c|c|}
\hline No & error source & $340 \mathrm{~nm}$ & $390 \mathrm{~nm}$ & $500 \mathrm{~nm}$ & $600 \mathrm{~nm}$ \\
\hline 1 & NIST lamp calibration & $1.09 \%$ & $1.09 \%$ & $0.91 \%$ & $0.91 \%$ \\
\hline 2 & long term drift of the NIST lamp & $0.96 \%$ & $0.96 \%$ & $0.87 \%$ & $0.87 \%$ \\
\hline 3 & calibration procedure & $5.07 \%$ & $3.29 \%$ & $2.58 \%$ & $2.48 \%$ \\
\hline 4 & UV/visible spectrometer stray light & $0.2 \%$ & $0.2 \%$ & $0.1 \%$ & $0.1 \%$ \\
\hline \multirow[t]{3}{*}{5} & telescope mirror reflectivity correction & & & & \\
\hline & and Langley correction error & $0.51 \%$ & $0.5 \%$ & $0.36 \%$ & $0.36 \%$ \\
\hline & total error & $\pm 5.3 \%$ & $\pm 3.63 \%$ & $\pm 2.89 \%$ & $\pm 2.8 \%$ \\
\hline
\end{tabular}

for well aligned point sources. When varying the distance $\mathrm{d}$ from $412.5 \mathrm{~cm}$ to $571.9 \mathrm{~cm}$ the following deviations from the square distance irradiance relation are found for the UV and visible spectrometer, respectively: maximum deviation $\pm 0.52 \% / \pm 0.5 \%$ with mean values of $\pm 0.12 \% / \pm 0.24 \%$. The small departures thus indicate the validity of our approach and that, laboratory stray light does not play a significant role in the calibration.

5. Since in the laboratory the whole optical set-up (the $500 \mathrm{~kg}$ gondola and the optical bench) can not be brought into all relative positions attained by the Suntracker and the Sun during a balloon flight (cf., the azimuth angle of the payload may change by as much as $15^{\circ}$, or the solar zenith angle may change from $65^{\circ}$ to $95^{\circ}$ before the Sun-tracker looses the tracking of the solar disk) the incident angle and wavelength dependent reflectivity of the Sun-tracker mirrors are measured in the laboratory by the SOPRA company (Paris/France) relative to the optical axis used in the absolute calibration. In fact, it is found that for the incident angles covered in the present study, the mirror reflectivity changes by as less $<3 \%$, therefore it is dealt with in the error budget (Table 1).

Table 1 summarizes the absolute errors in the absolute calibration of the DOAS-spectrometers and the $\mathrm{E}_{o}(\lambda)$ measurement (see Sect. 4.1). Arguable they are dominated by uncertainties arising from the calibration procedure (error source 3). The total error increases when going from the red into the UV-A spectral range, mostly because of the decreasing intensity the different calibration sources emit with decreasing wavelengths. This requires longer and longer signal integration periods (up to $15 \mathrm{~min}$ in the UV) in order to obtain reasonable signal to noise ratios for light detection. Although previous studies indicated that the used photodiode array detectors show a highly linear response for short integration times (seconds) typical in direct Sun spectroscopy, non-linearities, for example in the dark current, become more important with increasing integration time even though they are partly accounted for in the analysis (Ferlemann et al., 2000; Platt and Stutz, 2004). Therefore, a more accurate $\mathrm{E}_{o}(\lambda)$-measurement would require more intense emitting standard lamps than available, in particular in the UV-A spectral range.

\subsection{Absolute radiometric calibration of SCIAMACHY}

The absolute radiometric irradiance calibration of SCIAMACHY is based on the knowledge of two parameters: (1) a conversion factor for the measured detector signal (counts) and the absolute irradiance (or radiance), and (2) a correction factor taking into account the angular dependence of the mirror reflectivity and the Bi-directional Reflectance Distribution Function (BRDF) of the Elevation Scan Mechanism (ESM) diffuser. The first (throughput) factor is determined with the SCIAMACHY instrument under thermal vacuum conditions during several so-called "OPTEC" campaigns using NIST-calibrated lamps as irradiance reference and a combination of a NIST lamp and an external calibrated spectralon diffuser as radiance reference.

Since not all angular arrangements could be measured within the OPTEC campaigns, the second (scan angle dependent) factor is independently determined on 'a scanner module component level' under ambient conditions prior the OPTEC campaigns. More details about the SCIAMACHY calibration concept can be found in Frerick et al. (1997).

First comparisons of radiances and irradiances measured by SCIAMACHY with independent measurements indicated unreasonably large errors in its absolute radiometric calibration (Skupin et al., 2002). In order to resolve this problem, an extensive analysis of the radiometric on-ground calibration measurements of SCIAMACHY is performed, in which a new procedure is developed to recalculate some of the radiometric key data from existing end-to-end measurements. These calculations are primarily based on a subset of NASA integrated sphere measurements, performed within SCIAMACHY's radiance and irradiance validation during the OPTEC-5 period in 1999/2000. The employed integrating sphere is a $20^{\prime \prime}$ diameter internally illuminated sphere coated with $\mathrm{BaSO}_{4}$. It has a long history of providing accurate absolute radiances for the NASA SBUV2 and TOMS satellites and is also used for the validation of the 
Table 2. Compendium of LPMA/DOAS balloon-borne solar irradiance spectra measurements.

\begin{tabular}{|c|c|c|c|}
\hline Date/Time & Location & Geophys. Cond. & Instrument \\
\hline 23 March 2003 & Kiruna & \multirow{2}{*}{$\begin{array}{l}\text { high-lat. spring } \\
\text { sunset }\end{array}$} & \multirow{2}{*}{$\begin{array}{c}\text { LPMA+ } \\
\text { DOAS }\end{array}$} \\
\hline $14: 47-17: 35$ & $67.9^{\circ} \mathrm{N}, 21.1^{\circ} \mathrm{E}$ & & \\
\hline 9 Oct. 2003 & Aire-sur-l'Adour & \multirow{2}{*}{$\begin{array}{c}\text { mid-lat. fall } \\
\text { sunset }\end{array}$} & \multirow{2}{*}{$\begin{array}{c}\text { LPMA+ } \\
\text { DOAS }\end{array}$} \\
\hline 15:39-17:09 & $43.7^{\circ} \mathrm{N}, 0.25^{\circ} \mathrm{W}$ & & \\
\hline 24 March 2004 & Kiruna & \multirow{2}{*}{$\begin{array}{l}\text { high-lat. spring } \\
\text { sunset }\end{array}$} & \multirow{2}{*}{$\begin{array}{l}\text { LPMA+ } \\
\text { DOAS }\end{array}$} \\
\hline $13: 55-17: 35$ & $67.9^{\circ} \mathrm{N}, 21.1^{\circ} \mathrm{E}$ & & \\
\hline
\end{tabular}

GOME absolute radiance calibration. The inferred SCIAMACHY key data show differences to the on-ground ambient measured and calculated BRDF key data of SCIAMACHY's ESM diffuser. Using these new radiometric key data in the interpretation of in-flight measurements, significant improvements in the quality of the level-1 data products is achieved. From this improvement, a better quality of the SCIAMACHY level-2 data products can also be expected.

\section{Field observations}

\subsection{The LPMA/DOAS $\mathrm{E}_{o}(\lambda)$-measurements}

Prior to the balloon flights (see Table 2), the 3 balloon spectrometers are carefully calibrated with the on-site instrumentation and procedure described in Sects. 2.4 and 3.1. The LPMA/DOAS calibration procedure includes direct Sun observations at the ground during sunrise and sunset. These observations are used to control the optical alignment of the instruments (the Sun-tracker, and the spectrometer light intakes) installed aboard the gondola. Moreover the solar spectra recorded at the ground can also be used for comparisons with the in-flight taken spectra. Comparing both sets of data may provide new insights into total atmospheric scattering and absorption. This issue is particularly important to improve our understanding on the atmospheric absorption of the solar radiation, a scientific problem being intensively debated in the past years (e.g., Kerr, 1995; Arking, 1996; Harrison et al., 2003). These investigations will be reported elsewhere.

In the data analysis, the raw solar spectra measured during several balloon flights at balloon float altitude are first corrected for the so-called offset and dark current of the diode array detectors.

Further, the measured solar spectra need small but quantifiable corrections to account for the residual line-of-sight (LOS) atmospheric extinction (Rayleigh scattering) and absorption $\left(\mathrm{O}_{3}\right.$ and $\left.\mathrm{NO}_{2}\right)$. Owing to the balloon's high float altitude $(30.5-32.5 \mathrm{~km})$ and moderately large solar zenith angles (in the range of $83^{\circ}-88^{\circ}$ ), the total LOS air mass $\left(<2.5 \cdot 10^{24}\right.$ molecules $\left./ \mathrm{cm}^{2}\right)$ is very small compared to ground-based measurements. The corrections employed in

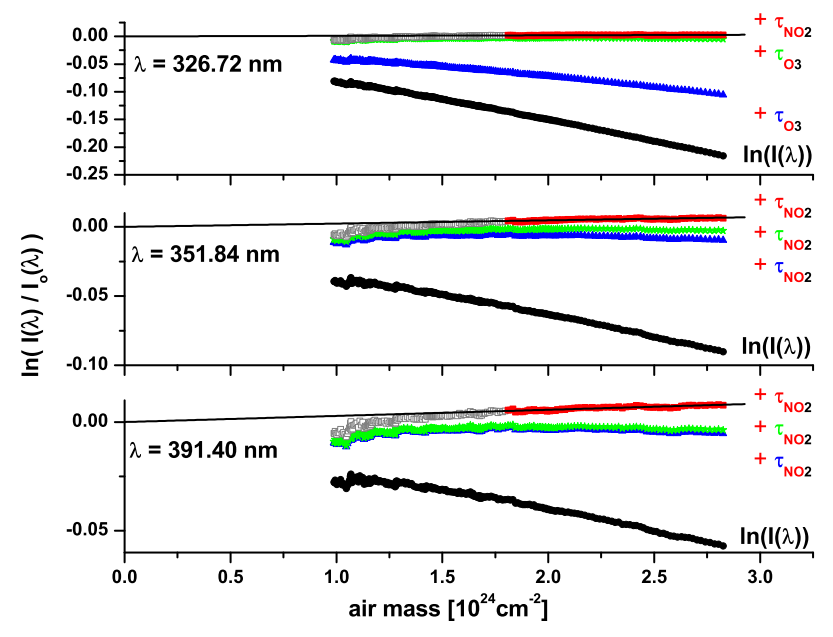

Fig. 1. Measured solar irradiance ratio $\left(\ln \left[\mathrm{E}(\lambda) / \mathrm{E}_{o}(\lambda)\right]\right)$ for $U V$ spectrometer at 3 wavelengths (upper panel: $326.7 \mathrm{~nm}$, middle panel: $351.8 \mathrm{~nm}$, lower panel: $391.4 \mathrm{~nm}$ ) inferred for the Aire-surl'Adour/France measurement around $\sim 32 \mathrm{~km}\left(83^{\circ}<S Z A<88^{\circ}\right)$ on 9 October 2003. The data in black show the measured $\ln \left[\mathrm{E}(\lambda) / \mathrm{E}_{o}(\lambda)\right]$, the data in blue, green and red after accounting for Rayleigh scattering, $\mathrm{O}_{3}$ absorption, and $\mathrm{NO}_{2}$ absorption, respectively. The open grey data are discarded in the Langley regression (for details see text) and the black lines show the regression to the Langley corrected data.

the present study rely on extrapolations to zero air mass of the calculated (Rayleigh) or DOAS-measured (for $\mathrm{O}_{3}$ and $\mathrm{NO}_{2}$ ) atmospheric extinction as a function of LOS (Langley's method) (Figs. 1 and 2).

The total LOS air masses are calculated from in-situ measured pressure (p) (accuracy $0.1 \mathrm{mbar}$ ) and temperature (T) (accuracy $0.5 \mathrm{~K}$ ), atmospheric model based $\mathrm{T}$ and p-profiles from the European Centre for Medium Range Weather Forecast (ECMWF) above balloon float altitude, and the Sun's ephemeris, using a ray tracing model. The lab-owned model accounts for a fully spherical and refractive atmosphere. From comparisons of the calculated air masses, and the known uncertainties in the atmospheric $\mathrm{T}$ and $\mathrm{p}$ profiles, the total accuracy for the LOS air mass is estimated to better than $\pm 5 \%$. Second, the measured spectra are corrected for the wavelength dependent Rayleigh scattering using the Rayleigh scattering cross section of Penndorf (1957), and the absorption of ozone and $\mathrm{NO}_{2}$ inferred from DOAS LOS absorption measurements of both gases (Ferlemann et al., 1998, 2000; for details on DOAS see Platt and Stutz, 2004). The accuracies for the LOS absorption of $\mathrm{O}_{3}$ and $\mathrm{NO}_{2}$ are estimated to $\pm 2 \%$ and $\pm 5 \%$, respectively.

As indicated in Figs. 1 and 2, the extinction corrections are not able to completely remove the small curvature in the measured irradiance vs total air mass plots, a finding which made us to speculate on the wavelength and angle dependence of the Sun-tracker mirrors (not correctly accounted 
for). Further from the comparison of the Sun-tracker mirror reflectivity and Langley corrected irradiance data in the overlapping wavelength range of the UV and visible instrument $(400-418 \mathrm{~nm})$, it is found that for LOS air masses $<2 \cdot 10^{24}$ molecules $/ \mathrm{cm}^{2}$ the UV channel shows an unreasonable decline in the measured $\mathrm{E}_{o}(\lambda)$. This decline corresponds to an apparent increase in the inferred optical thickness (OD) of $\triangle O D=0.012$ for a change in LOS air mass from 1 to $2 \cdot 10^{24}$ molecules $/ \mathrm{cm}^{2}$. This finding points to an extra low reflectivity spot on the Sun-tracker mirrors seen by the UV telescope for elevation mirror incident angles larger than $47.5^{\circ}$. Therefore in the further analysis, the UV data measured for LOS air masses $<2 \cdot 10^{24}$ molecules $/ \mathrm{cm}^{2}$ are discarded (the open symbols in Fig. 1). Also, since at present the reason for the remaining small curvatures in the Langley plots is not totally clear but fortunately small (maximum $\triangle \mathrm{OD} \leq 0.008$ in the UV channel), the corresponding uncertainties are dealt with in the error budget of the measurement (Table 1). Finally, the inferred $\mathrm{E}_{o}(\lambda)$ is also corrected for the varying Sun Earth distance, cf. by $-0.27 \%$ for the 9 October 2003 flight.

\subsection{The $\mathrm{E}_{o}(\lambda)$-measurement by SCIAMACHY}

Absolute $\mathrm{E}_{o}(\lambda)$-measurements of SCIAMACHY are performed in the ESM diffuser measurement cycle, on a daily basis. After the data are transmitted to the ground, they are processed by ESA which provides so called level I products to the users, including calibrated $\mathrm{E}_{o}(\lambda)$ spectra. For the present study, alternatively the SCIAMACHY $\mathrm{E}_{o}(\lambda)$ calibration from ESA, or the re-calibrated version of the IUPBremen is used for the ESA verification data set product from orbit 2499 (measured on 22 August 2002 and processed in November 2003). The ESA irradiance data set is currently expected to provide the best quality of the operational data.

For comparison with the correlative data, the SCIAMACHY $\mathrm{E}_{o}(\lambda)$-measurements are scaled to the mean SunEarth distance. Since the SCIAMACHY instrument has proven to be radiometrically very stable over time (Noël et al., 2003), no instrument degradation correction is applied to the data.

An additional correction is applied to the operational $\mathrm{E}_{o}(\lambda)$ considering the new results of the re-analysis of the onground calibration data performed by the IUP-Bremen (see Sect. 3.2). Using this correction, the radiometric key data used by the operational processing are essentially replaced. The quality of the IUP-Bremen correction is currently under investigation, and therefore the results presented here are still of 'preliminary' nature. It is found, however, that the corrected SCIAMACHY $\mathrm{E}_{o}(\lambda)$ are in good agreement with the MODTRAN $3.7 \mathrm{E}_{o}(\lambda)$ data in the visible channel (see below). The error of the IUP-Bremen corrected $\mathrm{E}_{o}(\lambda)$ is primarily arising from uncertainties in the on-ground calibration as indicated by consistency checks. They are expected to be in the order of $3-4 \%$ in the visible region somewhat larger in the UV.

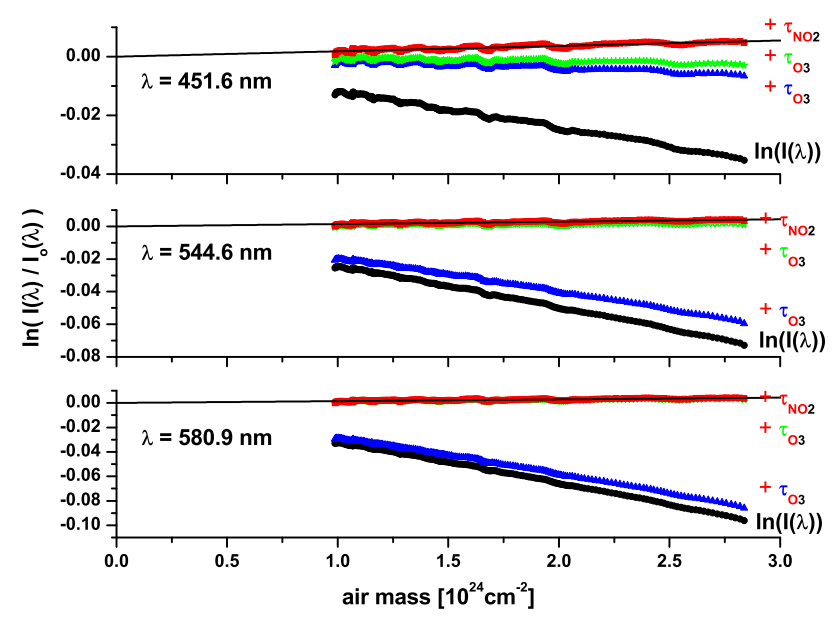

Fig. 2. Measured solar irradiance ratio $\left(\ln \left[\mathrm{E}(\lambda) / \mathrm{E}_{o}(\lambda)\right]\right)$ for visible spectrometer at 3 wavelengths (upper panel: $451.6 \mathrm{~nm}$, middle panel: $544.6 \mathrm{~nm}$, lower panel: $580.9 \mathrm{~nm}$ ) inferred for the Airesur-l'Adour/France measurement at $\sim 32 \mathrm{~km}\left(83^{\circ}<S Z A<88^{\circ}\right)$ on 9 October 2003. The data in black show the measured $\ln \left[\mathrm{E}(\lambda) / \mathrm{E}_{o}(\lambda)\right]$. The data in blue, green and red after accounting for Rayleigh scattering, $\mathrm{O}_{3}$ absorption, and $\mathrm{NO}_{2}$ absorption, respectively. The black lines show the regression to the Langley corrected data.

\section{Results and discussion}

Even though it is known that the solar activity does not greatly influence $\mathrm{E}_{o}(\lambda)$ in the considered wavelength ranges (e.g., Willson, 1997; IPCC, 2001), it is worthy to recall that prior to our balloon flight in early October 2003 the solar activity was low (for details see http://www.dxlc.com/solar/ history/hist2003.html), in particular when compared to the extreme solar activities reported for the year 2003 (see http:// sec.noaa.gov/ace/ACErtsw_home.html). Therefore, our measurement on 9 October 2003 can be regarded to be performed at moderately quiet Sun.

Figure 3 compares the UV/visible $\mathrm{E}_{o}(\lambda)$ spectra inferred from (a) our balloon observations (upper panel), (b) SCIAMACHY in channels 1 to 4 using the ESA (upper trace in panel b) and the IUP-Bremen calibration (lower trace in panel b), (c) inferred from SOLSPEC (Thuillier et al., 1997, 1998a, b), (d) from Kurucz et al. (1984) with updates recently given by Fontenla et al. (1999), and (e) from SORCE/SIM (Harder et al., 2000). Most striking features of the comparison are the exceedingly large $\mathrm{E}_{o}(\lambda)$ of SCIAMACHY (a) in the 597-605 $\mathrm{nm}$ wavelength range, and (b) in the whole $\mathrm{UV} /$ visible spectral range (upper trace in panel b) of the ESA calibration. While at present the reason for the former finding became clear in the meantime (etaloning) and has been removed in the Bremen calibration, finding (b) clearly points to a systematic error in the ESA level 1 calibration. Unravelling such errors, however, is one of the purposes of the present study. 


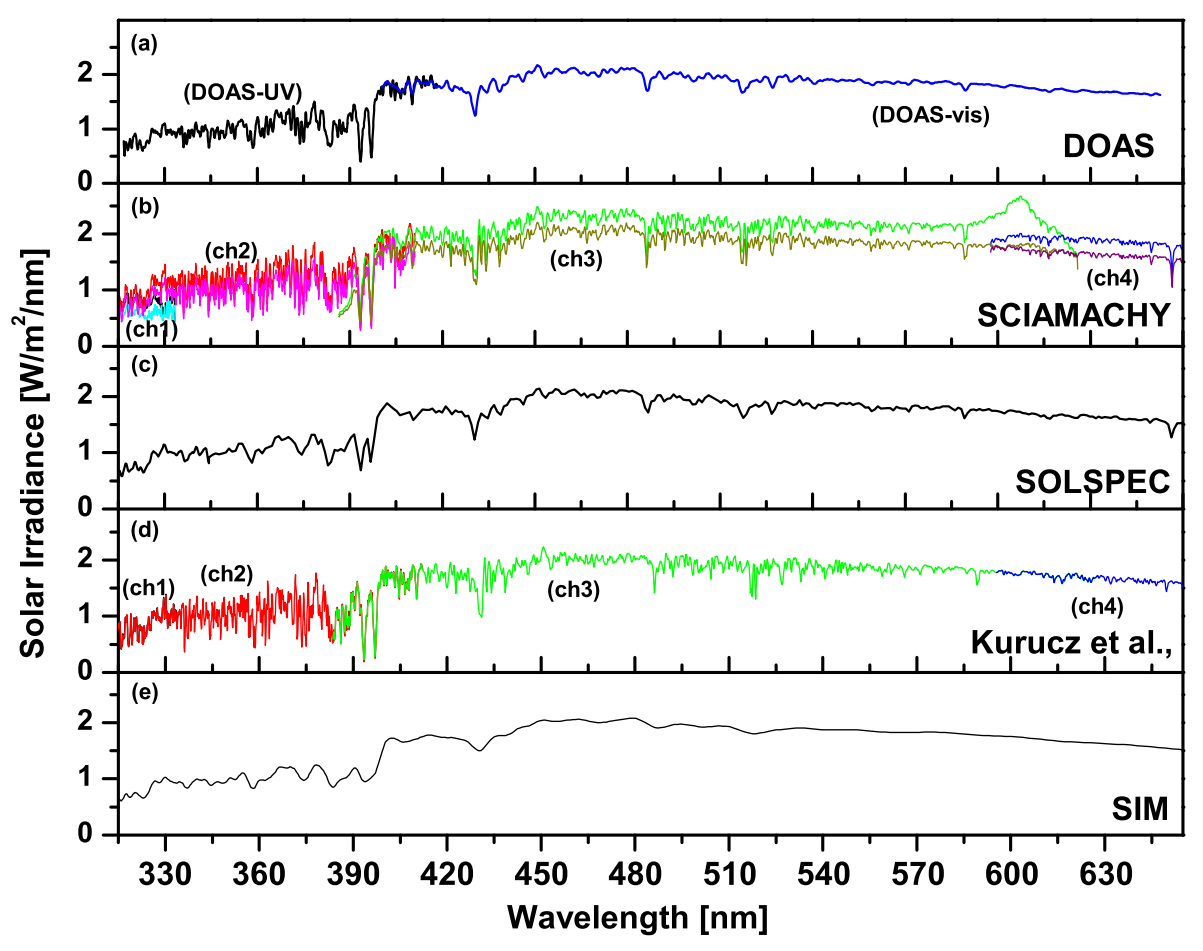

Fig. 3. Inter-comparison of measured solar irradiance spectra (a) for the DOAS measurements at Aire-sur-l'Adour at $32 \mathrm{~km}$, on 9 October 2003; (b) for SCIAMACHY/ENVISAT in channel 1, 2, 3, and 4 using the present ESA SCIAMACHY calibration (upper curves) and the revised IUP-Bremen calibration (lower curves); (c) from SOLSPEC (Thuillier et al., 1997, 1998a, b); (d) from Kurucz et al. (1984) with recent updates of Fontenla et al. (1999) (MODTRAN 3.7) and convolved to the spectral resolution of SCIAMACHY in the respective channels; (e) from SORCE/SIM (Harder et al., 2000).

Therefore, in the following only those $\mathrm{E}_{o}(\lambda)$ measurements are inter-compared which are apparently free from systematic errors. In the comparisons we refer all measured $\mathrm{E}_{o}(\lambda)$ to the high resolution measurements of Kurucz et al. (1994) with the updates given by Fontenla et al. (1999), i.e., MODTRAN 3.7, since it can be convolved to the actual spectral resolution of the former measurements using the WINDOAS software (M. Roozendael and C. Fayt, personal communication, 2000). Fitting two spectra to the resolution of the lower resolution spectrum (and by additional applying for $\lambda<418 \mathrm{~nm}$ a $1.5 \mathrm{~nm}$ wide Gaussian smoothing for the balloon and SCIAMACHY $\mathrm{E}_{o}(\lambda)$-measurements), however, minimizes the residuals in ratioed spectra due to slightly different line shapes of the recorded solar Fraunhofer lines while the weak wavelength dependence (baseline) is maintained (Fig. 4).

Most notably is the relative good agreement of the considered solar spectra for wavelength above $415 \mathrm{~nm}$, but the found departures are sometimes larger than the stated errors of the individual measurements.

In the visible spectral range $(415-652 \mathrm{~nm}$ after the reason for the dip in the SCIAMACHY measurements at $610 \mathrm{~nm}$ has been identified and removed), typical departures are $<1.7 \%$ (see Table 3 ). For the balloon measurements, a perfect agreement is found with the MODTRAN 3.7 spectrum within the 415-650 nm (agreement to within 0.03\%), but for the other sensors SOLPEC/ SORCE/SIM/SCIAMACHY is less $\operatorname{good}(-0.5 \%,-0.3 \%$, and $-0.4 \%)$, but well within the range given by the errors of the individual measurements. However, unlike in the SOLSPEC/MODTRAN 3.7, and SORCE/SIM/MODTRAN 3.7 inter-comparisons, neither in the balloon nor in the SCIAMACHY inter-comparison, the weakly wavelength dependent departure (from $+2 \%$ at $450 \mathrm{~nm}$ to $-2 \%$ at $625 \mathrm{~nm}$ ) is observed. Overall, beside the known deficits for SCIAMACHY, the comparison implies that our measured $\mathrm{E}_{o}(\lambda)$ spectrum is largely congruent with SOLSPEC, SORCE/SIM and the MODTRAN 3.7 Kurucz spectra, but not with the Kurucz et al. (1984) spectrum taking the Neckel and Labs (1984) calibration (for a comparison of MODTRAN 3.7 with the Kurucz et al., 1984 spectrum using the Neckel and Labs, 1984 calibration see Harrison et al., 2003). A similar conclusion is also drawn by Harrison et al. (2003), when comparing their $\mathrm{E}_{o}(\lambda)$-measurement with MODTRAN 3.7.

Conversely, in the UV spectral range $(316.7-370 \mathrm{~nm})$, the balloon, SORCE/SIM, SCIAMACHY, and SOLSPEC $\mathrm{E}_{o}(\lambda)$ spectra are all systematically lower (by $-4 \%,-6.2 \%$, $-5.2 \%,-1.3 \%$ respectively) than the MODTRAN 3.7 spectrum. This finding is also indicated in the Harrison et al. (2003) study even though their measurement went down 


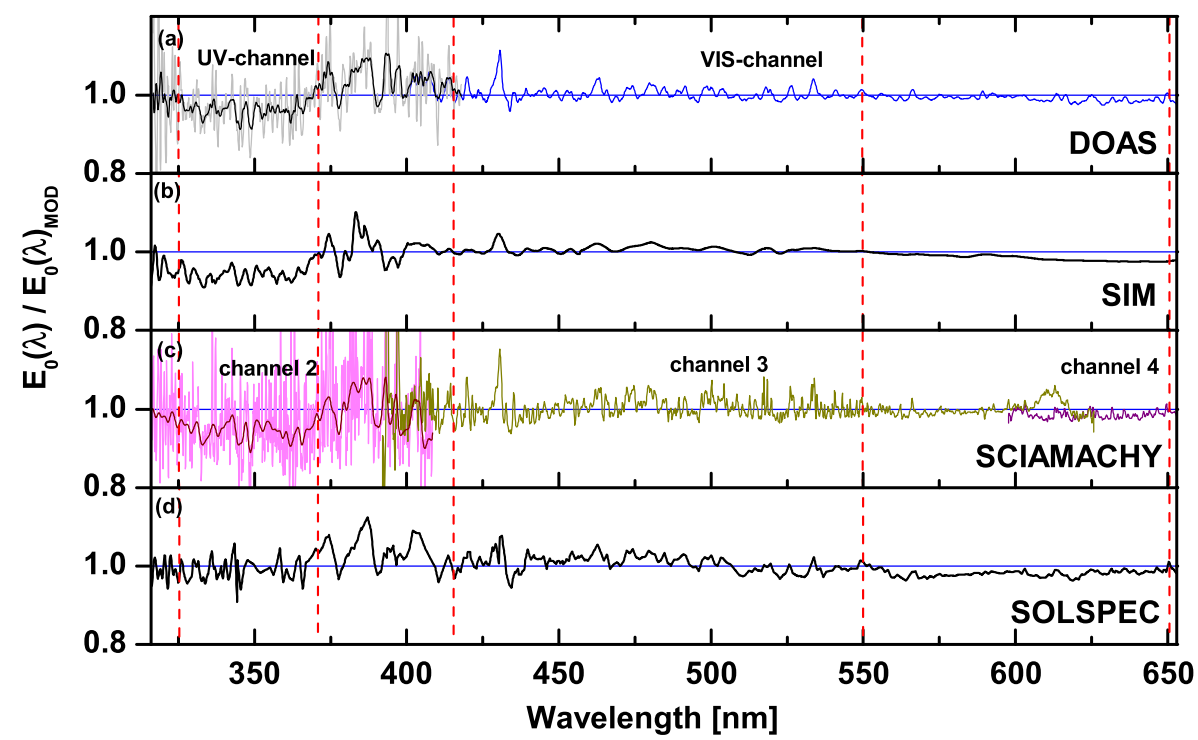

Fig. 4. Ratio of solar irradiance spectra $\left(\mathrm{E}_{O}(\lambda) / \mathrm{E}_{O}(\lambda) M O D\right.$ referenced to the solar spectrum of Kurucz et al. (1984) with recent updates of Fontenla et al. (1999) (MODTRAN 3.7) with (a) the present measurement, (b) SORCE/SIM (Harder et al., 2000), (c) SCIAMACHY/ENVISAT in channel 1, 2, 3, and 4 using the revised IUP-Bremen calibration, and (d) SOLSPEC (Thuillier et al., 1997, 1998, b). For comparison, the MODTRAN 3.7 solar spectrum is convolved to the spectral resolution of the individual instruments, using a least square fitted Gaussian instrument function as provided by the WINDOAS fitting tool. For the balloon and SCIAMACHY measurements, an additional $1.5 \mathrm{~nm}$ wide Gaussian smoothing is applied to the ratioed spectra (light grey and pink lines) for $\lambda<418 \mathrm{~nm}$ in order to illustrate baseline effects (filled black and pink lines, respectively). The red dashed lines separate the wavelength intervals for which the individual measurements are compared in Table 3.

to $360 \mathrm{~nm}$ only. Taking together all these results, there exists a body of evidence that the MODTRAN 3.7 solar spectrum overestimates the UV-A solar flux by several percent.

Within the 370-415 nm interval, the comparison does not provide a totally clear picture. Overall, out of the 4 solar spectra to which MODTRAN 3.7 are referred to 2 (our observation and the data rom SOLSPEC) show larger $\mathrm{E}_{o}(\lambda)$ $(\sim+2 \%)$ (as well as the Harrison et al., 2003 spectrum) than suggested by MODTRAN 3.7, but the other 2 are smaller $(-0.5 \%$, and $-1.7 \%$ for SORCE/SIM and SCIAMACHY, respectively). In distinct wavelength sub-intervals (e.g., at 370-376 nm, 381-387 nm, and 400-408), however, the departure of the individual spectra from MODTRAN 3.7 are larger (typically up to $10 \%$ ) even though the details may differ. This discrepancy may rather point to saturation effects due to strong solar Fraunhofer lines not properly accounted for when convolving the high resolution measurements of Kurucz et al. (1984) to the lower resolution balloon-borne, SORCE/SIM, SCIAMACHY and SOLSPEC measurements, than to a real discrepancy.

\section{Conclusions}

Our study allows the following conclusions and recommendations to be made:
1. We report on $\mathrm{E}_{o}(\lambda)$ measurements by LPMA/DOAS direct Sun observations performed at $32 \mathrm{~km}$ altitude. Overall our observation confirms previous $\mathrm{E}_{o}(\lambda)$ measurements within the given error bars. According to the discussion given above, the error of the present measurement is dominated by errors arising from the calibration procedure. In particular the dominating errors are due to the (1) relatively weak emissivity of the used calibration lamps in the UV-A spectral range, and (2) errors arising from remaining optical alignment errors. Certainly, both identified major error sources can further be diminished by taking appropriate measures in future measurements.

2. In the visible range $(435-650 \mathrm{~nm})$, our measured $\mathrm{E}_{o}(\lambda)$ compares well with previous $\mathrm{E}_{o}(\lambda)$-measurements of Kurucz et al. (1984) including the update given by Fontenla et al. (1999), SOLSPEC (Thuillier et al., 1997, 1998a, b) and SORCE/SIM (Harder et al., 2000). In agreement, with all other considered solar spectra (SORCE/SIM, SOLSPEC and SCIAMACHY using the IUP-Bremen calibration as well as those from Harrison et al., 2003), our balloon-borne measured $\mathrm{E}_{o}(\lambda)$ indicates that MODTRAN 3.7 is systematically too low in the UV-A $316.7-370 \mathrm{~nm}$ wavelength range. Further in the distinct several nm-wide wavelength bands within the $370-415 \mathrm{~nm}$ wavelength 
Table 3. Integrated solar irradiance $\left(\mathrm{W} / \mathrm{m}^{2}\right)$ in distinct wavelength intervals. The numbers in the brackets give the solar irradiance relative to MODTRAN 3.7 for dedicated wavelength intervals.

\begin{tabular}{lccccc}
\hline \multicolumn{5}{c}{ wavelength interval (nm) } \\
\hline present study & $325-370$ & $370-415$ & $415-550$ & $550-650$ & $325-650$ \\
SIM & $45.26(96,1 \%)$ & $59.66(102,1 \%)$ & $255.86(100,5 \%)$ & $174.41(99,4 \%)$ & $535.19(99,9 \%)$ \\
SCIAMACHY & $44.20(93,8 \%)$ & $58.18(99,5 \%)$ & $255.91(100,5 \%)$ & $172.82(98,5 \%)$ & $531.11(99,1 \%)$ \\
SOLSPEC & $46.49(94,3 \%)$ & $57.47(98,3 \%)$ & $254.74(100,0 \%)$ & $173.71(99,0 \%)$ & $530.33(99,0 \%)$ \\
MODTRAN 3.7 & 47.12 & $59.63(102,0 \%)$ & $256.33(100,7 \%)$ & $172.07(98,0 \%)$ & $534.52(99,8 \%)$ \\
\end{tabular}

interval, discrepancies among the individual spectra of up to $10 \%$ are found mostly due to saturation effects due to strong solar Fraunhofer lines not properly accounted for when convolving the high resolution measurements of Kurucz et al. (1984) to the lower resolution balloon, ENVISAT, SOLSPEC and SORCE/SIM measurements.

3. Our study also demonstrates that, the present ESA calibration implemented in the SCIAMACHY level 1 data processor needs to be changed c.f., to the data suggested by the IUP-Bremen re-calibration.

4. Further our study suggests that, by considering the available $\mathrm{E}_{o}(\lambda)$-measurements in the UV-A and visible wavelength interval (Table 3 ), the integrated $\mathrm{E}_{o}(\lambda)$ is uncertain by as much as $\sim 5 \mathrm{~W} / \mathrm{m}^{2}$. Relating this uncertainty in $\mathrm{E}_{o}(\lambda)$ in the UV-A and visible wavelength intervals to atmospheric absorption $(\mathrm{aA}=0.05)$, transmission $(\mathrm{T}=0.65)$, and albedo $(\mathrm{A}=0.3)$ of the Earth (IPCC, 2001), leads to the following (estimated) uncertainties when taken on a global average: $\Delta \mathrm{aA}=0.065 \mathrm{~W} / \mathrm{m}^{2}$, $\Delta \mathrm{T}=0.813 \mathrm{~W} / \mathrm{m}^{2}$, and $\Delta \mathrm{A}=0.375 \mathrm{~W} / \mathrm{m}^{2}$.

5. Since the solar irradiance is the driving force of the atmospheric photochemistry, the somewhat lower $\mathrm{E}_{o}(\lambda)$ found in the $370-410 \mathrm{~nm}$ wavelength interval and the systematically lower $\mathrm{E}_{o}(\lambda)$ in the $327-370 \mathrm{~nm}$ wavelengths range are accordingly expected to lower the photolysis frequencies of some important atmospheric trace gases (e.g., $\mathrm{NO}_{2}, \mathrm{BrO}, \mathrm{OClO}, \mathrm{IO}, \mathrm{OIO}, \ldots$ ), with the consequence of decelerating atmospheric photochemistry.

6. Finally, a better knowledge of $\mathrm{E}_{o}(\lambda)$ is very helpful for the solar cell industry (for $\mathrm{CuInSe}_{2}$ or amorphous $\mathrm{Si}$ cells threshold wavelengths are $\lambda=1378 \mathrm{~nm}$ and $\lambda=720 \mathrm{~nm}$, respectively) in order to (fine) adjust the wavelength dependent response of the solar cells.

An ASCII version of the $\mathrm{E}_{o}(\lambda)$-data is available on the www page http://www.iup.uni-heidelberg.de/institut/ institut/forschung/groups/atmosphere/stratosphere/ and a note should be sent to the authors if they are used for non-scientific purposes.
Acknowledgements. Support of the project by Bundesministerium für Bildung und Forschung (BMBF) through grant 50EE0017, and 50EE0019. Additional support came through the European Space Agency by the ESABC project (AO 146, AO 465, AO 629 and AO 694). We thank the technical team of LPMA (Y. Té, P. Jeseck, and V. Ferreira) for the assistance given to perform successfully the balloon flights. We are also grateful to the CNES teams "l'equippe nacelles pointées" and balloon launching team from Aire-sur-1'Adour/France without which the successful launch of the balloons would have been impossible. We also acknowledge the support given by Physikalisch-Technische Bundesanstalt (PTB) Braunschweig (A. Höpe und P. Sperfeld) in the commissioning of the absolute radiometric standards.

Edited by: M. Dameris

\section{References}

Arking, A.: Absorption of solar energy in the atmosphere: Discrepancy between model and observation, Science, 273, 779-782, 1996.

Bösch, H., Camy-Peyret, C., Chipperfield, M., Fitzenberger, R., Harder, H., Schiller, C., Schneider, M., Trautmann, T., and Pfeilsticker, K.: Inter comparison of measured and modeled stratospheric UV/vis actinic fluxes at large solar zenith angles, Geophys. Res. Lett., 28, 1179-1182, 2001.

Bösch, H., Camy-Peyret, C., Chipperfield, M. P., Fitzenberger, R., Harder, H., Platt, U., and Pfeilsticker, K.: Upper limits of stratospheric IO and OIO inferred from center-to-limb-darkeningcorrected balloon-borne solar occultation visible spectra: Implications for total gaseous iodine and stratospheric ozone, J. Geophys. Res., 108, D15, 4455, doi:10.1029/2002JD003078, 2003.

Bovensmann, H., Burrows, J. P., Buchwitz, M., Frerick, J., Noël, S., Rozanov, V. V., Chance, K. V., and Goede, A. H. P.: SCIAMACHY: Mission Objectives and Measurement Modes, J. Atmos. Sci., 56, 127-150, 1999.

Brault, J. and Neckel, H.: Unpublished solar spectra provided by Hamburger Sternwarte distributed through http://www.hs. uni-hamburg.de/DE/Oef/Inf/Einbl/Sospec/sonnspec.html, 1987.

Burrows, J. P., Hölzle, E., Goede, A. P. H., Visser, H., and Fricke, W.: SCIAMACHY - Scanning Imaging Absorption Spectrometer for Atmospheric Chartography, Acta Astronautica, 35, 7, 445-451, 1995. 
Camy-Peyret, C., Flaud, J. M., Perrin, A., Rinsland, C. P., Goldman, A., and Murcray, F.: Stratospheric $\mathrm{N}_{2} \mathrm{O}_{5}, \mathrm{CH}_{4}$ and $\mathrm{N}_{2} \mathrm{O}$ profiles from IR solar occultation spectra, J. Atmos. Chem., 16, 31-40, 1993.

Eichmann, K.-U., Kaiser, J. W., von Savigny, C., Rozanov, A., Rozanov, V., Bovensmann, H., König, M., and Burrows, J. P.: SCIAMACHY limb measurements in the UV/vis spectral region: first results, Adv. Space Res., 34, 775-779, 2003.

Ferlemann, F., Camy-Peyret, C., Fitzenberger, R., Harder, H., Hawat, T., Osterkamp, H., Perner, D., Platt, U., Schneider, M., Vradelis, P., and Pfeilsticker, K.: Stratospheric BrO profiles measured at different latitudes and seasons: Instrument description, spectral and profile retrieval, Geophys. Res. Lett., 25, 38473850, 1998.

Ferlemann, F., Bauer, N., Fitzenberger, R., Harder, H., Osterkamp, H., Perner, D., Platt, U., Schneider, M., Vradelis, P., and Pfeilsticker, K.: A new DOAS-instrument for stratospheric balloonborne trace gas studies, J. Applied Optics, 39, 2377-2386, 2000.

Fitzenberger, R., Bösch, H., Camy-Peyret, C., Chipperfield, M. P., Harder, H., Platt, U., Sinnhuber, B.-M., Wagner, T., and Pfeilsticker, K.: First Profile Measurements of Tropospheric BrO, Geophys. Res. Lett., 27, 2921-2924, 2000.

Fontenla, J., White, O. R., Fox, P. A., Avrett, E. H., and Kurucz, R. L.: Calculation of solar irradiances, I. Synthesis of the solar spectrum, Astrophys. J., 518, 480-500, 1999.

Frerick, J., Bovensmann, H., Noël, S., Burrows, J. P., and Dobber, M.: SCIAMACHY on-ground and in-flight calibration, performance verification and monitoring concepts, edited by: Barnes, W. L., Proc. of SPIE, Earth Observing Systems II, 3117, 176187, 1997.

Harder, H., Camy-Peyret, C., Ferlemann, F., Fitzenberger, R., Hawat, T., Osterkamp, H., Perner, D., Platt, U., Schneider, M., Vradelis, P., and Pfeilsticker, K.: Stratospheric BrO Profiles Measured at Different Latitudes and Seasons: Atmospheric Observations, Geophys. Res. Lett., 25, 3843-3846, 1998.

Harder, H., Bösch, H., Camy-Peyret, C., Chipperfield, M., Fitzenberger, R., Payan, S., Perner, D., Platt, U., Sinnhuber, B., and Pfeilsticker, K.: Comparison of measured and modeled stratospheric BrO: Implications for the total amount of stratospheric bromine, Geophys. Res. Lett., 27 , 3695-3698, 2000.

Harder, J., G. Lawrence, G. Rottman, and T. Woods, The Spectral Irradiance Monitor (SIM) for the SORCE Mission, Proc. SPIE, 4135, pp. 204-214, see: http://lasp.colorado.edu/sorce/ presentation/SORCE_Brochure_10_25_FINAL.pdf, 2000.

Harrison, L., Kiedron, P., Berndt, J., and Schlemmer, J.: Extraterrestrial solar spectrum 360-1050 nm from Rotating Shadowband Spectroradiometer measurements at the Southern Great Plains (ARM) site, J. Geophys. Res., 108, D14, 4424, doi:10.1029/2001JD001311, 2003.

Hawat, T. M., Camy-Peyret, C., and Torguet, R. J.: A Suntracker for atmospheric remote sensing, Optical Engineering, 37(05), 16331642, 1998.

Huguenin, D.: Design and performance of stratospheric balloonborne platforms for infrared astrophysical observations, Infrared Phys. Techno., 35 (2/3), 195-202, 1994.

IPCC: Third Assessment Report - Climate Change 2001: WMO, Geneve, Switzerland, 2001.

Kerr, R. A.: Darker clouds promise brighter future for climate models, Science, 267, 454, 1995.
Kurucz, R. L.: The solar spectrum, in: The Solar Interior and Atmosphere, edited by: Cox, A. N., Livingston, W. C., and Matthews, M., University of Arizona Press, Tucson, Ariz., 663-669, 1992.

Kurucz, R. L., Furenhild, I., Brault, J., and Testermann, L.: Solar flux atlas from 296 to $1300 \mathrm{~nm}$, National Solar Observatory Atlas No. 1, June 1984, (ftp://ftp.noao.edu/fts/fluxatl), 1984.

Neckel, H. and Labs, D.: The solar radiation between 3300 and $12500 A^{\circ}$, Sol. Phys., 90, 205-258, 1984.

Noël, S., Wuttke, M. W., Skupin, J., Bovensmann, H., Burrows, J. P., Gottwald, M., and Krieg, E.: The SCIAMACHY instrument on ENVISAT: First performance monitoring results, Proc. of International Geoscience and Remote Sensing Symposium (IEEEIGARSS), Learning from Earth's shapes and colors, 21-25 July 2003, Toulouse, France, 2003.

Payan, S., Camy-Peyret, C., Lefèvre, F., Jeseck, P., Hawat, T., and Durry, G.: First direct simultaneous $\mathrm{HCl}$ and $\mathrm{ClONO}_{2}$ profile measurements in the Arctic vortex, Geophys. Res. Lett., 25, 2663-2666, 1998.

Penndorf, R.: Table of the refractive index for standard air and the Rayleigh scattering coefficient for the spectral region between 0.2 to $20.0 \mu \mathrm{m}$ and their application to atmospheric optics, J. Opt. Soc. Am. 47, 176-182, 1957.

Pfeilsticker, K., Sturges, W. T., Bösch, H., Camy-Peyret, C., Chipperfield, M. P., Engel, A., Fitzenberger, R., Müller, M., Payan, S., and Sinnhuber, B.-M.: Lower stratospheric organic and inorganic bromine budget for the arctic winter 1998/99, Geophys. Res. Lett., 27, 3305-3308, 2000.

Pfeilsticker, K., Bösch, H., Camy-Peyret, C., Fitzenberger, R., Harder, H., and Osterkamp, H.: First Atmospheric Profile Measurements of UV/visible $\mathrm{O}_{4}$ Absorption Band Intensities: Implications for the Spectroscopy, and the Formation Enthalpy of the $\mathrm{O}_{2}-\mathrm{O}_{2}$ Dimer, Geophys. Res. Lett., 28 , 4595-4598, 2001.

Platt, U. and Stutz, J.: Differential optical absorption spectroscopy (DOAS), Principle and Applications, Springer Verlag Heidelberg, ISBN 3-340-21193-4, 2004.

Rozanov, A., Rozanov, V., and Burrows, J. P.: A numerical radiative transfer model for a spherical planetary atmosphere: Combined differential-integral approach involving the Picard iterative approximation, JQSRT, 69, 491-512, 2001.

Skupin, J., Noël, S., Wuttke, M. W., Bovensmann, H., and Burrows, J. P.: Calibration of SCIAMACHY in-flight measured irradiances and radiances-first results of level 1 validation, Proc. of the Envisat Validation Workshop (SP-531), ESA Publications Division, 2002.

Thuillier, G., Hersé, M., Simon, P. C., Labs, D., Mandel, H., and Gillotay, D.: Observation of the UV solar irradiance between 200 and $350 \mathrm{~nm}$ during the ATLAS-1 mission by the SOLSPEC spectrometer, Sol. Phys., 171, 283-302, 1997.

Thuillier, G., Hersé, M., Simon, P. C., Labs, D., Mandel, H., Gillotay, D., and Foujols, T.: The visible solar spectral irradiance from 350 to $850 \mathrm{~nm}$ as measured by the SOLSPEC spectrometer during the ATLAS-1 mission, Sol. Phys., 177, 41-61, 1998a.

Thuillier, G., Hersé, M., Simon, P. C., Labs, D., Mandel, H., and Gillotay, D.: Solar radiometry and solar spectral irradiance: Observation of the solar spectral irradiance from $200 \mathrm{~nm}$ to $870 \mathrm{~nm}$ during the ATLAS 1 and ATLAS 2 missions by the SOLSPEC spectrometer, Metrologia, 35, 689-697, 1998b. 
Von Savigny, C., Rozanov, A., Bovensmann, H., Eichmann, K.-U., Kaiser, J. W., Noël, S., Rozanov, V. V., Sinnhuber, B.-M., Weber, M., and Burrows, J. P.: The Ozone hole break-up in September 2002 as seen by SCIAMACHY on ENVISAT, J. Atmos. Sci., 62(3), 721-734, 2005a.

Von Savigny, C., Kokhanovsky, A., Bovensmann, H., Eichmann, K.-U., Kaiser, J., Noël, S., Rozanov, A. V., Skupin, J., and Burrows, J. P.: NLC Detection and Particle Size Determination: First Results from SCIAMACHY on ENVISAT, Adv. Space. Res., 34(4), 851-856, 2005 b.
Walker, K. D., Saunders, R. D., Jackson, J. K., and Mc Sparron, D. A.: Spectral Irradiance Calibration, NBS Special Publication, 250-20, 1987.

Wehrli, C.: Extraterrestrial solar spectrum, Publ. 615, Phys.Meteorol. Obs., Davos and World Radiat. Cent., Davos-Dorf, Switzerland, 1985.

Willson, R. C.: Total solar irradiance trend during solar cycles 21 and 22, Science, 277, 1963-1965, 1997. 